Table 1. Prevalence of parasitic infection in captive elephants in Guruvayoor

\section{INCIDENCE OF HELMINTHIC INFECTION AMONG ANNUALLY DEWORMED CAPTIVE ELEPHANTS}

\author{
P.C. Saseendran ${ }^{1}$, S. Rajendran ${ }^{2 *}$, H. Subramanian ${ }^{3}$, M. \\ Sasikumar $^{2}$, G. Vivek ${ }^{2}$ and K.S. Anil ${ }^{4}$
}

${ }^{1}$ Professor and Head, ${ }^{2}$ Postgraduate Scholar, ${ }^{4}$ Assistant Professor, Department of Livestock Production Management; ${ }^{3}$ Associate Professor and Head, Department of Veterinary Parasitology, College of Veterinary and Animal Sciences, Mannuthy, Thrissur, Kerala 680651, India.

*Corresponding author: 13/9, Thiru. Vi. Ka. Street, Veerappan chatram, Erode, Tamil Nadu 638004, India.

Email:cvsrajesh@yahoo.co.in

Large number of elephants in captivity in Kerala are susceptible to a number of ailments, particularly parasitic diseases. Gastrointestinal nematodes in elephants are very common and have been responsible for frequent illness. Hence the present study was carried out to assess the prevalence of parasitic infections in captive elephants in the Punnathoor Kotta of Guruvayoor Devasom Board, Guruvayoor $\left(10^{\circ} 34^{\prime} \mathrm{N}, 7^{\circ} 00^{\prime} \mathrm{E}\right)$ which is a temple town in the coastal belt of Thrissur District, Kerala. The elephant camp has 58 elephants which have been dewormed annually for the past five years. Dung samples were collected from 44 and 55 elephants during the year 2000 and 2002 respectively. The collected dung samples were preserved in $10 \%$ formalin and brought to the laboratory for screening of parasitic eggs. The samples were examined by concentration and centrifugation method as per Georgi (1985).

Prevalence of parasitic infections in elephants is given in Table 1. Out of the 99 samples, $17(17.17 \%)$ were positive for parasitic infection. During the year 2000, the incidence of parasitic infection was $22.73 \%$ whereas it was only $12.73 \%$ in 2002 . Among the positive samples, 10 samples (10.10\%) had strongyles and seven (7.07\%) had amphistomes. Chakraborty and Islam (1996) and Gaur et al. (1979) had reported 58\% and $62.5 \%$ parasitic infection in elephants respectively.

In all the previous studies, incidence of strongyle infection in captive elephants were reported to be high (Guar et al., 1979; Chandrasekharan et al., 1982; Dutta \& Bordoloi, 1989; Roa et al., 1992; Cheeran, 1999). Chandrasekharan (1992) reported $91.27 \%$ strongylosis in captive elephants, maintained by the forest department. Suresh et al. (2001) recorded 63.64\% and $87.5 \%$ strongylosis at S.V. Dairy Farm, Tirupati and Nehru

\begin{tabular}{|c|c|c|c|c|}
\hline \multirow[t]{2}{*}{ Year } & \multirow{2}{*}{$\begin{array}{l}\text { No. of samples } \\
\text { examined }\end{array}$} & \multicolumn{2}{|c|}{ No. of positive samples } & \multirow[b]{2}{*}{ Total } \\
\hline & & Strongyle & Amphistome & \\
\hline 2000 & 44 & 7 (15.91\%) & $3(6.82 \%)$ & $10(22.73 \%)$ \\
\hline 2002 & 55 & $3(5.45 \%)$ & $4(7.27 \%)$ & $7(12.73 \%)$ \\
\hline Total & 99 & $10(10.10 \%)$ & $7(7.07 \%)$ & $17(17.17 \%)$ \\
\hline
\end{tabular}

Zoological Park, Hyderabad respectively.

Amphistomosis were also identified by Huang (1981), Chandrasekharan et al. (1982) and Dutta and Bordoloi (1989). Chandrasekharan (1992) observed $17.85 \%$ amphistomosis in captive elephants, the prevalence being significantly higher than the present observation.

The low incidence of helminthic infection in Punathoor Kotto might be due to regular annual deworming with albendazole @ $2.5 \mathrm{mg} / \mathrm{kg}$ body weight. Chandrasekharan (1992) and Suresh $e t$ al. (2001) had also reported the effectiveness of albendazole against strongylosis in elephants. Therefore it is advisable to deworm elephants once in 6-12 months to prevent the harmful effects caused by parasites.

\section{References}

Chakraborty, A. and S. Islam (1996). A survey of gastrointestinal parasitic infections in some free-living herbivores in the Kaziranga National Park. Zoos' Print 11(3): 3-5.

Chandrasekharan, K. (1992). Prevalence of infectious diseases in elephants in Kerala and their treatment. In: The Asian Elephant: Ecology, Biology, Diseases, Conservation and Management. Kerala Agricultural University, 148-155pp.

Chandrasekharan, K., K. Radhakrishnan, J.V. Cheeran, K.N.M. Nair and K.N. Ramanujam (1982). Comparative efficiency of six anthelmintics against strongylosis in elephants. Kerala Journal of Veterinary Science 13(1): 15-20.

Cheeran, J.V. (1999). Habitat utilization of animals and their parasitic burden with the special reference to elephants in Vazhachal forest division, Kerala. Zoos' Print 14(2): 44.

Dutta, G.C. and Bordoloi (1989). Prevalence of helminthic infection in elephants of Tiger Project of Manas, Assam. Zoos' Print 4(3): 14. Gaur, S.N.S., M.S. Sethi, H.C. Tewari and O. Prakash (1979). A note on the prevalence of helminth parasites in wild and zoo animals in Uttar Pradesh. Indian Journal of Animal Science 49(2): 159-161.

Georgi, J.R. (1985). Parasitology for Veterinarians. $4^{\text {th }}$ edition. W.B. Saunders, London, 334pp.

Huang, D.S. (1981). Three trematodes parasitizing an elephant (Elephas maximus). Chinese Journal of Veterinary Medicine 7(4): 17-18. Rao, D.S.T., S. Yathiraj, P.C. Choudhuri and K.P. Reddy (1992). Treatment of helminthiosis in elephants. Indian Journal of Animal Science 62(12): 1155-1156.

Suresh, K., P.C. Choudhuri, K.N. Ajithkumar, Md. Hafeez and P.A. Hamza (2001). Epidemiological and clinico-therapeutic studies of strongylosis in elephants. Zoos' Print Journal 16(7): 539-540. 